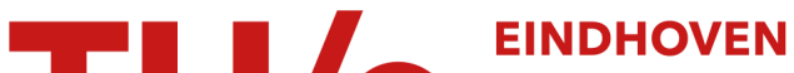 UNIVERSITY OF TECHNOLOGY
}

\section{Experimental frequency-domain method for control design in heavy-duty vehicles}

\section{Citation for published version (APA):}

van der Zalm, G. M., Huisman, R. G. M., \& Steinbuch, M. (2005). Experimental frequency-domain method for control design in heavy-duty vehicles. In Proceedings of the 16th IFAC World Congress, July 4-8, 2005, Prague, Czech Republic (pp. 6-). Elsevier. https://doi.org/10.3182/20050703-6-CZ-1902.01932

DOI:

10.3182/20050703-6-CZ-1902.01932

Document status and date:

Published: 01/01/2005

\section{Document Version:}

Accepted manuscript including changes made at the peer-review stage

\section{Please check the document version of this publication:}

- A submitted manuscript is the version of the article upon submission and before peer-review. There can be important differences between the submitted version and the official published version of record. People interested in the research are advised to contact the author for the final version of the publication, or visit the $\mathrm{DOI}$ to the publisher's website.

- The final author version and the galley proof are versions of the publication after peer review.

- The final published version features the final layout of the paper including the volume, issue and page numbers.

Link to publication

\section{General rights}

Copyright and moral rights for the publications made accessible in the public portal are retained by the authors and/or other copyright owners and it is a condition of accessing publications that users recognise and abide by the legal requirements associated with these rights.

- Users may download and print one copy of any publication from the public portal for the purpose of private study or research.

- You may not further distribute the material or use it for any profit-making activity or commercial gain

- You may freely distribute the URL identifying the publication in the public portal.

If the publication is distributed under the terms of Article $25 \mathrm{fa}$ of the Dutch Copyright Act, indicated by the "Taverne" license above, please follow below link for the End User Agreement:

www.tue.nl/taverne

Take down policy

If you believe that this document breaches copyright please contact us at:

openaccess@tue.nl

providing details and we will investigate your claim. 


\title{
EXPERIMENTAL FREQUENCY-DOMAIN METHOD FOR CONTROL DESIGN IN HEAVY-DUTY VEHICLES
}

\author{
G. van der Zalm**, R. Huisman*, M. Steinbuch** \\ * DAF Trucks NV, PO Box 90065, 5600 PT Eindhoven, The Netherlands \\ ** Eindhoven University of Technology, Department of Mechanical Engineering, \\ PO Box 513, 5600 MB Eindhoven, The Netherlands
}

\begin{abstract}
The large parameter variations in heavy-duty trucks make it very difficult to find appropriate settings for fixed structure speed controllers. Satisfying the design specifications with experience-based trial-and-error methods for the control design is very time-consuming. This paper discusses the use of experimental frequency domain methods for the tuning of speed controllers. The focus is on the cruise control, but the method is also applicable to other speed controllers. Experimental results are given to validate the approach. Copyright $@ 2005$ IFAC
\end{abstract}

Keywords: Automotive control, control design, PI controllers, closed-loop identification

\section{INTRODUCTION}

Heavy-duty vehicles are equipped with many control systems, well-known examples being vehicle speed and stability control. DAF Trucks NV, a producer of trucks in Eindhoven, The Netherlands, equips its trucks with more than 50 controllers. Approximately ten of these controllers are related to the control of vehicle or engine speed, e.g. cruise control or speed limiters. They are all of the PID-type, possibly extended with filters.

These controllers have to be tuned to satisfy certain driveability performance and stability requirements. Currently, the controller tuning is done by experience based trial-and-error. This has the disadvantage that there is no guarantee for stability or performance robustness for other vehicle configurations unless a large number of experiments is carried out. Other disadvantages are that this method gives no insight in possible improvements and that it is very time consuming.

Common tuning techniques for PID-controllers are based on the method developed by Ziegler and Nichols (Ziegler and Nichols, 1942). These methods are widespread in the process industry. Their main advantages are that they are simple to use and that no explicit model knowledge is required. However, it is implicitly assumed in these methods that the underlying processes are overcritically damped. Therefore they are not suitable for application to vehicular drivelines since generally these drivelines are weakly damped and, hence, show strong mechanical resonances. The frequency and magnitude of these resonances vary largely with vehicle weight and selected gear ratio. When these dynamics are neglected, the performance of the closed-loop system can deteriorate and stability can be hampered. Finally, using the Ziegler-Nichols related methods it is not possible to tune the system to satisfy predefined performance specifications.

The problems related to mechanical resonances are also encountered in motion control of mechanical systems like robots. In this field, it is common to apply frequency domain techniques for controller tuning (Steinbuch and Norg, 1998). These techniques can only be used if the relevant behavior of the system can be described with acceptable accuracy by a linear model. For these systems, they offer the possibility to tune for performance and stability robustness. The required models can be obtained by applying first principles of physics, by experimental identification or by a combination of these methods. This paper discusses the use of these frequency domain methods in the tuning of speed controllers. The main focus will be on cruise control tuning, but the proposed method is also applicable for other speed controllers. First, the modelling will be done using three methods: physical modelling, step response experiments based modelling and frequency response function (FRF) measurement. Next, the controller structure will be discussed and the tuning will be done using loop shaping (Franklin, et al., 1994). Experimental results will be given to validate the approach. Finally, conclusions and recommendations will be given. 


\section{MODELLING AND IDENTIFICATION}

\subsection{System description}

Figure 1 gives a schematic representation of the driveline of a truck. The torque delivered by the engine is reduced by the gearbox and transmitted to the differential by the propulsion shaft. Two drive shafts transmit the torque from the differential to the rear wheels. The mass of this truck combined with a loaded trailer can vary between $7000 \mathrm{~kg}$ and 40,000 $\mathrm{kg}$. The to-be-controlled quantity is the vehicle speed $v$. Here, the emphasis is on cruise control in straightforward driving on horizontal roads, since no measurement of the road slope is available. Neither engine braking nor braking by the friction brakes and/or the retarder are considered. The cruise control has to operate for vehicle speeds between 30 and 90 $\mathrm{km} / \mathrm{h}$.

The available measurement of the vehicle speed is delivered by an inductive cog wheel sensor at the output shaft of the gearbox. The output of this sensor is transmitted to the controller via the CAN-bus of the truck. The vehicle speed $v$ is estimated from this signal. In the following, this estimation will be referred to as the vehicle speed.

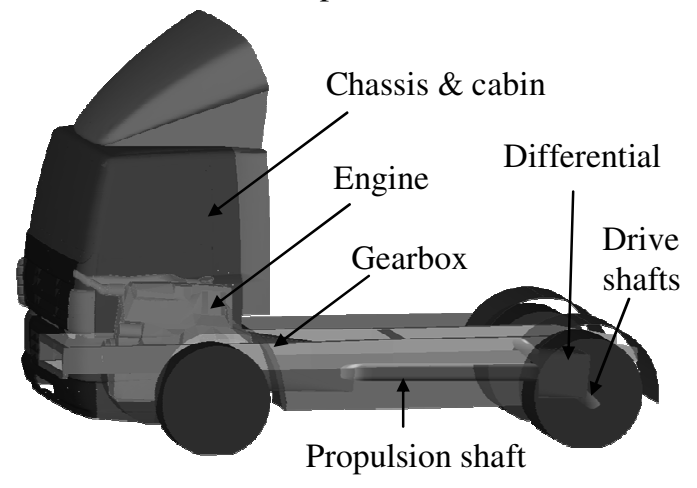

Fig. 1. Overview of the drive-train

In all measurements, a truck with a 12 gear automated manual transmission is used. This truck is equipped with a dSPACE MicroAutoBox, on which a MATLAB/Simulink scheme is running that communicates with the electronic control unit of the engine using the CAN-bus of the truck.

\subsection{Physical modelling}

It is assumed that the clutch is closed whenever the cruise controller is active and that all deformations in the engine, the clutch, the gearbox and the connecting shafts between these parts may be neglected. The propulsion shaft between the gearbox and the differential and the drive shafts between the differential and the wheels are assumed to behave as linear, deformable bodies. Because only straight-on driving is considered here, the two drive shafts may be combined into one equivalent drive shaft.
The main external forces acting on the vehicle are the wheel slip force and the air resistance, defined as:

$$
\begin{aligned}
& F_{\text {slip }}=c_{\text {slip }} \frac{R \omega_{w}-v}{R \omega_{w}} \\
& F_{\text {air }}=c_{a} v^{2}
\end{aligned}
$$

Where $c_{\text {slip }}$ is the wheel slip coefficient, which depends on the normal force on the driven wheels, $\omega_{w}$ the angular velocity, $R$ the radius of the driven wheels, and $c_{a}$ a constant drag factor. Further nonlinear forces are due to the energy dissipation in the gearbox and the differential. It is assumed that these losses are proportional to the angular velocity of the corresponding shaft.

Since the controller has to realize a constant, prescribed speed $v_{0}$, it is obvious to linearise nonlinear effects around a stationary operating point. This operating point is defined by (i) the vehicle weight, (ii) the vehicle speed, and (iii) the selected gear. Assuming that $R \omega_{w, 0}=v_{0}$, linearization of equation (1) results in:

$$
\begin{aligned}
& F_{\text {slip }}=\frac{c_{\text {slip }}}{v_{0}}\left(R \omega_{w}-v\right), \\
& F_{\text {air }}=2 c_{a} v_{0} v
\end{aligned}
$$

Figure 2 shows a simplified linear representation. The stiffness and damping of the propulsion and drive shafts are lumped into one spring $k$ and damper $b_{2}$, taking into account the ratio of the gearbox and differential. The three inertia $J_{1}, J_{2}$, and $J_{3}$ represent the engine, the wheels and the chassis respectively, and $\varphi_{1}, \varphi_{2}$, and $\varphi_{3}$ are the corresponding angular rotations.

The wheel slip is modelled by the damper $b_{4}$ between the wheels and the chassis inertia. The three dampers $b_{1}, b_{3}$, and $b_{5}$ represent the losses due to gear box inefficiency, differential inefficiency, and air resistance respectively.

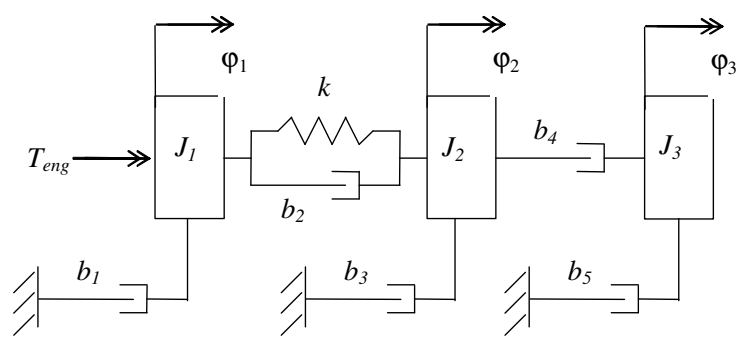

Fig. 2. Linear representation of the drive-train

The engine torque is assumed to be proportional to the injected fuel:

$$
T_{\text {eng }}=c_{\text {eng }} f_{\text {in }},
$$

where $c_{\text {eng }}$ is the engine constant.

The state space representation of this model equals:

$$
\begin{aligned}
& \dot{x}=A x+B u \\
& y=C x+D u
\end{aligned}
$$




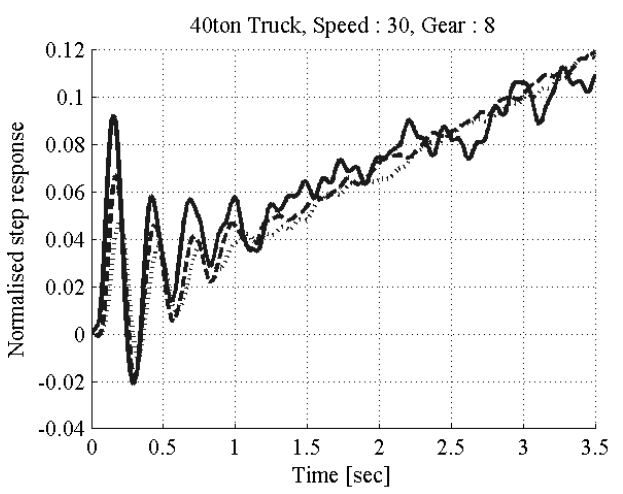

Fig. 3. Normalised step responses for amplitudes $10 \%(-), 20 \%(--)$, and $30 \%$ (:)

where

$$
\begin{aligned}
& x=\left[\begin{array}{lllll}
\varphi_{1} & \dot{\varphi}_{1} & \varphi_{2} & \dot{\varphi}_{2} & \dot{\varphi}_{3}
\end{array}\right]^{T}, \\
A= & {\left[\begin{array}{ccccc}
0 & 1 & 0 & 0 & 0 \\
-\frac{k}{J_{1}} & -\frac{\left(b_{1}+b_{2}\right)}{J_{1}} & \frac{k}{J_{1}} & \frac{b_{2}}{J_{1}} & 0 \\
0 & 0 & 0 & 1 & 0 \\
\frac{k}{J_{2}} & \frac{b_{2}}{J_{2}} & -\frac{k}{J_{2}} & -\frac{\left(b_{2}+b_{3}+b_{4}\right)}{J_{2}} & \frac{b_{4}}{J_{2}} \\
0 & 0 & 0 & \frac{b_{4}}{J_{3}} & -\frac{\left(b_{4}+b_{5}\right)}{J_{3}}
\end{array}\right] } \\
B= & {\left[\begin{array}{ccccc}
0 & \frac{c_{\text {eng }} i_{g b}}{J_{1}} & 0 & 0 & 0
\end{array}\right]^{T} } \\
C= & 3.6 \frac{R}{i_{\text {diff }}}\left[\begin{array}{lllll}
0 & 1 & 0 & 0 & 0
\end{array}\right], \quad D=0
\end{aligned}
$$

where $i_{g b}$ is the gearbox ratio, $i_{\text {diff }}$ is the differential ratio, $y$ the vehicle speed in $\mathrm{km} / \mathrm{h}$, and $u$ the injected fuel in $\mathrm{mg} /$ stroke.

\subsection{Step response based modelling}

Here, the approximate realisation theory (Schutter, 2000 ) is utilised to estimate a model from a measured step response. It should be noted that a step response excites the lower frequencies more than the higher frequencies, resulting in a less accurate model for the high-frequency dynamics. For a linear system, the normalised responses to different input amplitudes should be the same. Therefore, each step response $y$ is normalised by the step size and shifted in time resulting in $y_{\text {norm }}$ :

$$
y_{\text {norm }}(t)=\frac{y\left(t-t_{0}\right)}{\Delta u},
$$

where $t_{o}$ is the starting time, and $\Delta u$ the amplitude of the stepwise fuel injection.

The models used for the controller tuning should cover the complete operating range of interest. To this end, step response measurements have been performed at various speeds for two gears for which the desired cruise speed is attainable. In addition the vehicle weight is varied between the two extreme lading conditions and different amplitudes of the stepwise input are used.

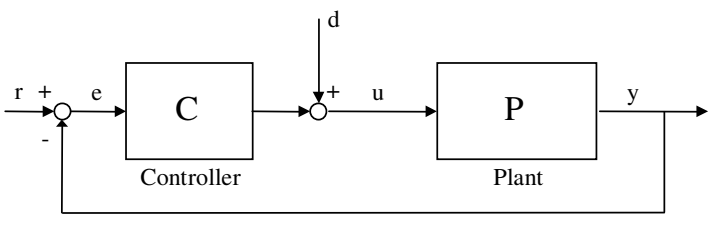

Fig. 4. Experimental setup for closed loop sensitivity measurement

As an example, figure 3 shows the normalised responses for a 40 ton truck driving $30 \mathrm{~km} / \mathrm{h}$ in gear 8. It can be concluded that the slopes after the oscillation in the normalised responses are approximately the same. However, the amplitude of the oscillation seems to decrease for higher input amplitudes, indicating non-linear behaviour. This behaviour is neglected, and it is assumed further on that the system is linear. A final observation is that a time delay of approximately $70 \mathrm{~ms}$ is visible in all measurements. This time delay is caused by the sampling on the CAN-bus, and a delay in the engine dynamics.

Due to the large influence of measurement noise (mainly harmonic, due to sensor misalignment) on the calculation of the model, it is necessary to filter the data. The choice for model order and the used time span of the step response have a large influence on the resulting model. A longer time span gives a better low-frequency estimation at the cost of less accurate high-frequency estimation. Here, these factors have been compromised in such a way that the resulting models are reliable for low frequencies.

\section{$2.4 \quad$ FRF measurement}

For frequency domain identification, sensitivity measurements are performed (Ljung, 1999). During the measurements, a PI-controller is used to keep the velocity near the desired operating point, as depicted in figure 4 , where the reference trajectory $r$ is kept constant. The input $d$ is the excitation of the plant and contains frequencies that are relevant for the identification. The transfer function from the excitation $d$ to the plant input $u$ is called the sensitivity, estimated with:

$$
\hat{S}=\frac{P_{d u}}{P_{d d}}
$$

where $P_{d u}$ is the cross-spectral density between $d$ and $u$, and $P_{d d}$ is the autospectrum of $d$. Since the controller transfer function is exactly known it is possible to reconstruct an estimate for $P$ with:

$$
\hat{P}=\frac{1-\hat{S}}{C \hat{S}}
$$

Experiments have been done with low-pass filtered white noise inputs containing frequencies up to 40 $\mathrm{Hz}$ in the same operating point as described above. 

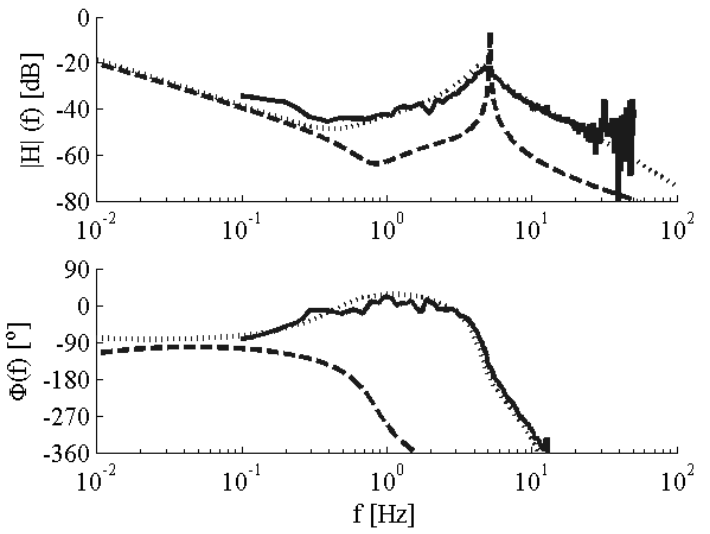

Fig. 5. Models for a 40 ton truck driving $50 \mathrm{~km} / \mathrm{h}$ in gear 9; FRF (-), step (--), and physical (:)

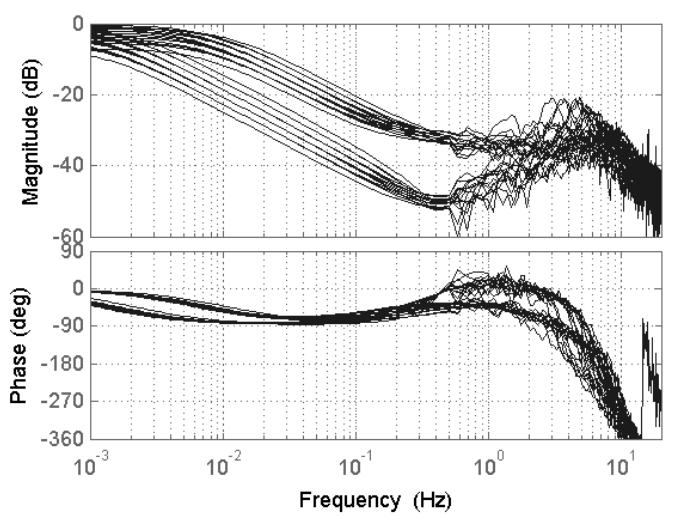

Fig. 6. Bode plots of the models for all operating points

\subsection{Model comparison}

Figure 5 shows the resulting models for a 40 ton truck driving in gear 9 at $50 \mathrm{~km} / \mathrm{h}$. Some of the parameters of the physical model are estimated by using the reconstructed plant FRF. In addition, a lowpass filter and a delay are added to the physical model to fit the measured FRF for high frequencies. The need for this low-pass filter can be explained by the engine dynamics.

Based on this figure and the earlier considerations, the following observations, valid throughout the entire operating range, can be made:

- The tuned physical model is able to predict the behaviour of the truck very well. Hence, the model structure seems to be sufficient.

- The estimated model based on the step response is reliable for low frequencies, but the high frequency behaviour is not captured properly.

- The FRF estimates are reliable for high frequencies, but not for low frequencies. This is indicated by the coherence functions (not shown), which show that the FRF estimates are reliable for frequencies higher than $0.5 \mathrm{~Hz}$. It should be noted that there are just a few data points for low frequencies, i.e. at $0.1 \mathrm{~Hz}$ and at $0.2 \mathrm{~Hz}$.

- The time delay is clearly visible in the FRF measurements as an increasing phase lag. By plotting the phase on a linear scale the time delay is estimated equal to 60 [ms], which is approximately the same as observed from the step responses.

Based on these observations a combination of the step response based model and the FRF estimate is constructed and used for the tuning of the controller. The step response based models are used for the low frequency region, whereas the FRF estimates are used for the high frequency region. The physical model is useful for the evaluation of the influence of configuration changes. In figure 6 , the Bode plots of the combined models for all operating points are shown.

\section{CONTROLLER TUNING}

\subsection{Controller structure}

The controller used at DAF for all types of speed control is a PI-controller in series with a first order filter:

$$
C(s)=\frac{K_{P} s+K_{I}}{s} \frac{1}{\tau s+1},
$$

where $K_{P}$ is the proportional gain, $K_{I}$ is the integral gain, and $\tau$ is the time constant of the low-pass first order filter. Additional features are an integral antiwindup, and the possibility to use two sets of PIgains, called low gain and high gain. In the implemented controller, the value for $\tau$ has to be the same for low gain and high gain.

The low gain will be tuned for all operating points, and the high gain will be used to increase the performance in operating points with a high vehicle weight and high vehicle speed.

\subsection{Performance and stability specifications}

The driveability performance specifications are expressed in terms of step response related quantities: - The overshoot $M_{P}$ is the maximum amount the system overshoots its final value, divided by its final value.

- The rise time $t_{r}$ is the time it takes the system to reach its final value for the first time.

Franklin, et al. (1994) relate these quantities with the natural frequency $\omega_{o}$ and the specific damping $\zeta$ for an undercritically damped second order system:

$$
\begin{aligned}
& t_{r}=\frac{1.8}{\omega_{0}} \\
& M_{p}=e^{\frac{\pi \zeta}{\sqrt{1-\zeta^{2}}}}
\end{aligned}
$$

These relations for a second order system can be used as a rough approximation for other systems. 


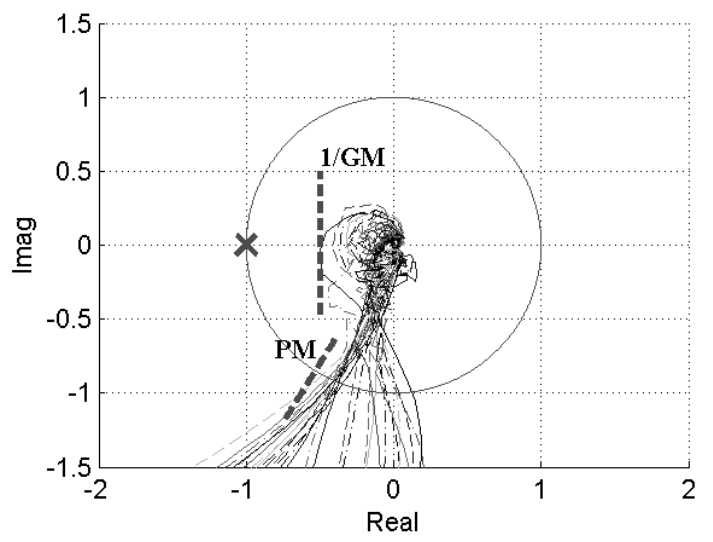

Fig. 7. Nyquist plots for the low gain controller setting with all operating points.

With $\omega_{o}$ as an approximation for the desired bandwidth ${ }^{1} \omega_{b w, d e s}$, equations (10) are used to specify the performance criteria for the closed loop system.

The classical quantities used to assess stability robustness are the gain margin $G M$ and the phase margin $P M$. GM is the factor by which the gain can be multiplied before the Nyquist curve of the open loop intersects the point $(-1,0)$, and $P M$ is the amount by which the phase of the open loop can be decreased before the open loop intersects $(-1,0)$. For $P M \leq 70^{\circ}$, the relative damping $\zeta$ may be approximated by (Franklin, et al, 1994):

$$
\zeta \approx \frac{P M}{100}
$$

with $P M$ in degrees. Using equations (11) and (12), it is possible to calculate a desired $P M_{\text {des }}$ from the specification on the overshoot $M_{P}$. The value for the desired gain margin $G M_{d e s}$ is initially set to 2, as recommended by Åström and Hägglund (1995).

\subsection{Tuning approach}

The specifications derived above have to be achieved for all operating points. This is done by tuning the low gain of the controller, such that it satisfies the specifications for all operating points. The high gain of the controller is tuned for a smaller set of operating points, namely for vehicle speeds above 70 $\mathrm{km} / \mathrm{h}$ and gears higher than 10 .

The approach taken here is to identify a worst-case operating point in the set of operating points, and then use loop shaping on this worst-case model to find the controller parameters $K_{P}$ and $\tau$ such that the specifications are satisfied. The value for $K_{I}$ is maximised, since this leads to better load disturbance attenuation (Åström and Hägglund, 1995). This maximisation is done using all operating points, since using the worst-case only gives no guarantee that the

\footnotetext{
${ }^{1}$ The bandwidth of the system is defined here as the $0 \mathrm{~dB}$ crossover frequency of the magnitude of $P(s) C(s)$.
}
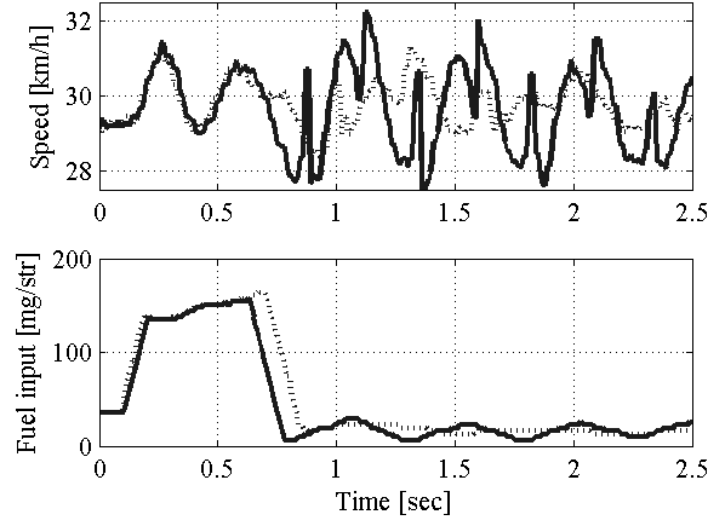

Fig. 8. Vehicle speed (upper) and fuel injection response (lower) to a stepwise disturbance in the fuel input for $G M=2$ (solid line) and increased $G M$ (dashed line)

desired $P M$ is achieved for all models.

An analysis with the physical model shows that the worst-case operating point is the truck with the highest vehicle weight, driving with the lowest vehicle speed in the lowest gear. In the case of tuning the low gain of the cruise control, this means that the the worst case model is a 40 ton truck driving 30 $\mathrm{km} / \mathrm{h}$ in gear 7 .

The value for the proportional action $K_{P}$ is chosen such that the desired bandwidth is reached for the worst-case, according to:

$$
K_{P}=\frac{1}{\left|\hat{P}_{\text {worst }}\left(j \omega_{b w, d e s}\right)\right|}
$$

Next, the value for $\tau$ is chosen such that the desired value for $G M_{d e s}$ is achieved for the worst-case model. This guarantees stability for all operating points. Finally, $K_{I}$ is maximised under the constraint that the desired $P M$ is satisfied for all operating points.

The same stepwise procedure is taken for the high gain set of the cruise control, but with the model of the truck driving $70 \mathrm{~km} / \mathrm{h}$ in gear 10 as the worstcase.

\subsection{Tuning results}

Figure 7 shows the resulting Nyquist plots for the low gain of the controller for the relevant operating points. All open loop transfers satisfy the specified $G M$ and $P M$. It can be concluded that the outlined approach results in controller settings that achieve the specifications for all operating points.

\section{EXPERIMENTAL VALIDATION}

First, the stability of the worst-case operating point for low gain is assessed. Figure 8 shows the response to a tip-in disturbance, i.e. the driver pressing the accelerator pedal for approximately 0.6 seconds. The response shows a weakly damped oscillation. A 
cause for this oscillation can be the neglected nonlinearity of the resonance amplitude, or the driveline backlash or friction, which is not taken into account in the control design. The latter nonlinear effects are known to cause limit cycles (Hensen, 2002), and several solutions to this problem have been proposed, involving nonlinear control laws or adding a load observer (Lagerberg and Egardt, 2002; Nordin and Gutman, 2002).

However, since the controller structure is fixed, the approach taken here to solve this problem is to reduce the high-frequency control action by increasing GM. To achieve this, the value for $\tau$ has to be increased. Experimentally, it turned out that an increased $G M$ gave subjectively good results. This is shown in figure 8 as the dashed line.

The consequence of a higher $G M$ is that the bandwidth has to be lowered to allow integral action. In a test in which the setpoint is changed from 30 to $40 \mathrm{~km} / \mathrm{h}$, the overshoot is within the specifications for all operating points. An example is shown in figure 9. However, due to the large operating range of the low gain the value for the integral gain is rather low, which results in sluggish settling behaviour. For the driver of the truck, this effect is barely noticeable, so this behaviour is judged acceptable.

\section{CONCLUSIONS \& RECOMMENDATIONS}

The three presented modelling methods are complementary in the sense that the step response based method results in reliable low-frequent models, the FRF measurements give a reliable model for high frequencies, and the physical model is useful for interpretation of experimental results and evaluating configuration changes.

The presented frequency domain tuning method offers the possibility to tune the speed controllers in heavy-duty trucks in a structured way. The use of stability and performance criteria as tuning parameters is faster and more robust than trial-anderror or Ziegler-Nichols related methods.

Experimental results show that the controllers resulting from the tuning method meet the specifications.

It is recommended to implement a controller structure which is able to use a vehicle weight estimate to change its parameters. This gives the possibility to use an increased integral gain, which improves the disturbance attenuation.

In future work an effort will be made to automate the tuning process by means of an optimisation algorithm. This eliminates the loop shaping by hand.

\section{ACKNOWLEDGEMENT}

The authors like to thank Frans Veldpaus for his valuable contribution to this work.

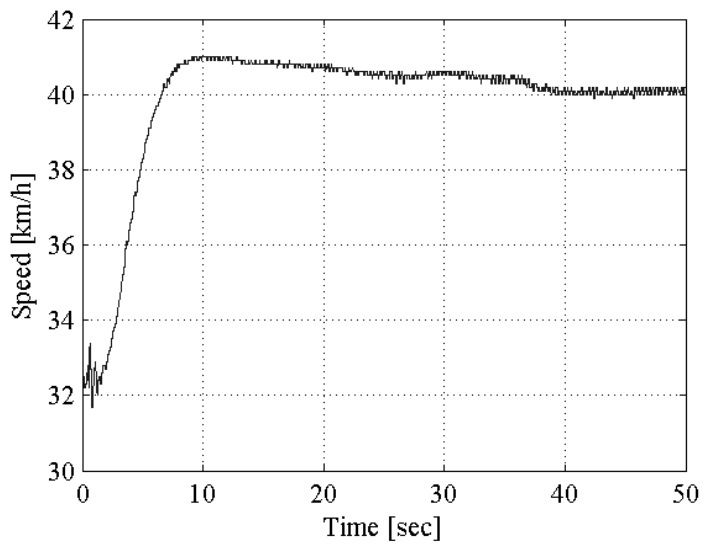

Fig. 9. Vehicle speed response for a 40 ton truck driving $32 \mathrm{~km} / \mathrm{h}$ in gear 7

\section{REFERENCES}

Åström, K.J. and T. Hägglund (1995). PID Controllers: Theory, Design, and Tuning. Research Triangle Park: Instrument Society of America.

Franklin, G.F., J. David Powell and A. EmamiNaeini (1994). Feedback control of dynamic systems. Addison-Wesley Publishing Co., Amsterdam.

Hensen, R.H.A. (2002). Controlled Mechanical Systems with Friction. Ph.D. Thesis, University Press Facilities, Eindhoven.

Lagerberg, A. and B.S. Egardt (2002). Control of backlash in automotive powertrains. Presented at Reglermöte 2002, Linköping, Sweden.

Ljung, L. (1999). System identification: theory for the user. Upper Saddle River: Prentice Hall.

Nordin, M. and P.-O. Gutman (2002). Controlling mechanical systems with backlash - a survey. Automatica, 38, pp. 1633-1649.

Schutter, B. de (2000). Minimal state-space realization in linear system theory: An overview. Journal of Computational and Applied Mathematics, Special Issue on Numerical Analysis in the 20th century - Vol. I: Approximation Theory, 121, pp. 331-354.

Steinbuch, M. and M.L. Norg, (1998). Advanced Motion Control: an industrial perspective, European J. of Control, 4, pp. 278-293.

Ziegler, J.G. and N.B. Nichols, (1942). Optimum settings for Automatic Controllers. Trans. ASME, 64, pp.759-768. 